\title{
Activation of p53 contributes to pseudolaric acid $B$-induced senescence in human lung cancer cells in vitro
}

\author{
Guo-dong YAO ${ }^{1}$, Jing YANG ${ }^{1}$, Qiang $\mathrm{LI}^{1}$, Ye ZHANG ${ }^{1}$, Min QI ${ }^{2}$, Si-miao FAN ${ }^{3}$, Toshihiko HAYASHI ${ }^{1}$, Shin-ichi TASHIRO ${ }^{4}$,
} Satoshi ONODERA ${ }^{5}$, Takashi IKEJIMA ${ }^{1, *}$

${ }^{1}$ China-Japan Research Institute of Medical and Pharmaceutical Sciences, Shenyang Pharmaceutical University, Shenyang 110016, China; ${ }^{2}$ Tianjin Taiyang Pharmaceutical Co, Ltd, Tianjin 300457, China; ${ }^{3}$ Tianjin University of Traditional Chinese Medicine, Tianjin 300193, China; ${ }^{4}$ Institute for Clinical and Biomedical Sciences, Kyoto 603-8072, Japan; ${ }^{5}$ Department of Clinical and Pharmaceutical Sciences, Showa Pharmaceutical University, Tokyo 194-8543, Japan

Aim: Pseudolaric acid B (PAB), a diterpene acid isolated from the root bark of Pseudolarix kaempferi Gordon, has shown to exert antitumor effects via inducing cell cycle arrest followed by apoptosis in several cancer cell lines. Here we reported that PAB induced a mitotic catastrophe in human lung cancer A549 cells, which resulted in senescence without apoptosis or necrosis.

Methods: Three human lung cancer cell lines (A549, H460 and H1299 cells) were examined. Cell growth inhibition was assessed with MTT assay. Cell cycle distribution was determined using a flow cytometer. Cell nuclear morphology was observed under a fluorescence microscope. Senescent cells were detected using SA- $\beta$-Gal staining. Apoptotic and senescent protein expression was examined using Western blot analysis. The expression of p53 and p21 in the cells was downregulated by siRNAs.

Results: Treatment with PAB $(5-80 \mu \mathrm{mol} / \mathrm{L})$ inhibited the growth of A549 cells in dose- and time-dependent manners. Prolonged treatment with PAB $(20 \mu \mathrm{mol} / \mathrm{L})$ caused $\mathrm{G}_{2} / \mathrm{M}$ arrest at day 1 followed by mitotic catastrophe from day 2 , which eventually resulted in cell senescence between days 3 and 4 without cell death (apoptosis or necrosis). Knockdown of p53 expression with siRNA significantly suppressed PAB-induced senescence in A549 cells (p53 wild). Furthermore, PAB-induced senescence was also observed in human lung cancer H460 cells (p53 wild), but not in human lung cancer H1299 cells (p53 null).

Conclusion: The anti-tumor action of PAB against human lung cancer A549 cells in vitro involves the induction of senescence through activation of the p53 pathway.

Keywords: pseudolaric acid B; human lung cancer; $\mathrm{G}_{2} / \mathrm{M}$ arrest; mitotic catastrophe; senescence; SA- $\beta$-Gal; $p 12 ; p 53$

Acta Pharmacologica Sinica (2016) 37: 919-929; doi: 10.1038/aps.2016.8; published online 4 Apr 2016

\section{Introduction}

Pseudolaric acid B (PAB), a traditional Chinese medicine, is the principal compound isolated from the root bark of Pseudolarix kaempferi Gordon. It exerts potent anti-fungal, anti-tumor, anti-fertility and anti-microtubule effects ${ }^{[1]}$. Accumulating evidence suggests that PAB exhibits its anti-tumor activity by inducing cell cycle arrest followed by apoptosis in several cell lines, including melanoma A375 and human cervical carcinoma HeLa cells ${ }^{[2-4]}$, PAB-induced senescence accompanied apoptosis in the human breast cancer cell line MCF-7 and murine fibrosarcoma L929 cells ${ }^{[5,6]}$. Previous studies indicate

\footnotetext{
* To whom correspondence should be addressed. E-mail ikejimat@vip.sina.com

Received 2015-10-28 Accepted 2016-01-24
}

that $\mathrm{PAB}$ is not cytotoxic to normal human peripheral blood mononuclear cells and primary mouse dermal fibroblast cells ${ }^{[6,7]}$.

Mitotic catastrophe is characterized by the appearance of enlarged cells with multiple micronuclei and the decondensation of chromatin ${ }^{[6,8]}$. The fates of cells suffering from mitotic catastrophe vary from one cell line to another, depending on the type of antimitotic drug ${ }^{[9]}$. In most cases, these cells eventually die via apoptosis or necrosis; however, some cells undergo an irreversible growth arrest, namely senescence ${ }^{[10]}$.

Senescence is a process by which cells enter a state of permanent cell cycle arrest. Senescent cells are viable and retain their metabolic activity; although, they lose their proliferative capacity $^{[11]}$. The current concept of the biological meaning of cellular senescence is extended to the functions in biological processes such as embryonic development, wound healing, 
tissue repair and organismal ageing ${ }^{[12]}$. The induction of cellular senescence in tumor cells is a favorable therapeutic strategy for tumor suppression ${ }^{[13]}$. Experimental evidence indicates that the induction of senescence in cancer therapy has benefits, such as low toxicity-related side effects and immune stimulation $^{[14,15]}$. Thus, understanding the causes and consequences of cellular senescence provides us a novel tumor therapy, particularly for the chronic management of some cancers, allowing patients to maintain a quality and quantity of life ${ }^{[16]}$.

This study reports that PAB induces a mitotic catastrophe in A549 cells, which results in senescence without apoptosis or necrosis.

\section{Materials and Methods Reagents}

PAB and paclitaxel (taxol) of $99 \%$ purity were obtained from the National Institutes for Food and Drug Control (Beijing, China). PAB was dissolved in dimethylsulfoxide (DMSO) as a stock solution. The concentration of DMSO was kept below $0.1 \%$ in all of the cell cultures so as not to induce any detectable effects on cell growth. 3-(4,5-Dimethyl-2-thiazolyl)-2,5-diphenyl-2- $H$-tetrazolium bromide (MTT), propidium iodide (PI), RNase A, 4',6'-diamidino-2-phenylindole dihydrochloride (DAPI), and Z-VAD-fmk (ZVAD) were purchased from Sigma Chemical (St Louis, MO, USA). Primary antibodies against p-p53, p53, p21, cyclin B1, p-Histone 3, caspase 3 and $\beta$-actin, as well as the horseradish peroxidase-conjugated secondary antibodies, were purchased from Santa Cruz Biotechnology (Santa Cruz, CA, USA). The SuperSignal ${ }^{\circledR}$ West Pico Chemiluminescent Substrate for horseradish peroxidase (HRP) was obtained from Thermo Scientific (Rockford, IL, USA).

\section{Cell culture}

Three human lung cancer cell lines (A549, H460 and H1299 cells) were obtained from the American Type Culture Collection (ATCC, Manassas, VA, USA). The A549 cells were cultured in DMEM (Gibco, NY, USA) supplemented with $10 \%$ fetal bovine serum (FBS) , $100 \mathrm{U} / \mathrm{mL}$ penicillin and 100 $\mu \mathrm{g} / \mathrm{mL}$ streptomycin. The H460 and H1299 cells were cultured in RPMI-1640 medium containing 10\% FBS, $100 \mathrm{U} / \mathrm{mL}$ penicillin and $100 \mu \mathrm{g} / \mathrm{mL}$ streptomycin. The cells were incubated at $37^{\circ} \mathrm{C}$ with $5 \% \mathrm{CO}_{2}$ in a humidified atmosphere. Logarithmically growing cells were used in all of the experiments.

\section{Growth inhibition assay}

The growth inhibition of the PAB-treated A549 cells was measured using an MTT assay. The cells were seeded into 96-well cell culture clusters (Corning, NY, USA) at a density of $4 \times 10^{3}$ cells per well. After a $24 \mathrm{~h}$ incubation, the cells were treated with various concentrations of PAB for 1 to $4 \mathrm{~d}$. Thereafter, the cells were rinsed twice with PBS and incubated with 100 $\mu \mathrm{L}$ of a $0.5 \mathrm{mg} / \mathrm{mL}$ MTT solution at $37^{\circ} \mathrm{C}$ for $3 \mathrm{~h}$. After removing the supernatant, the formazan crystals formed by the MTT were dissolved with $150 \mu \mathrm{L}$ of DMSO. The absorbance at 492 $\mathrm{nm}$ was measured using a microplate reader (Thermo Scientific Multiskan MK3, Shanghai, China). The cell growth inhi- bition was calculated as follows:

$$
\text { Inhibition ratio } \begin{aligned}
(\%)= & \left(A_{492}, \text { control }-A_{492, \text { sample }}\right) / \\
& \left(A_{492}, \text { control }-A_{492, \text { blank }}\right) \times 100
\end{aligned}
$$

\section{Analysis of cell cycle by flow cytometry}

After the cells were treated with PAB for the time periods indicated, they were collected and fixed in $70 \%(v / v)$ ethanol at $4{ }^{\circ} \mathrm{C}$ overnight. Then, the specimen fixed were rinsed with PBS twice and stained with $0.5 \mathrm{~mL}$ of the PI solution (PI 50 $\mu \mathrm{g} / \mathrm{mL}$ and RNase $1 \mathrm{mg} / \mathrm{mL}$ ) at $4{ }^{\circ} \mathrm{C}$ in the dark for $30 \mathrm{~min}$. The samples were analyzed with a FACScan flow cytometer (Becton Dickinson, Franklin Lakes, NJ, USA).

\section{Observation of morphological changes}

The cells were treated with $20 \mu \mathrm{mol} / \mathrm{L} \mathrm{PAB}$ for different time periods, and the cellular morphology was observed using phase contrast microscope (Olympus, Tokyo, Japan). After staining with $10 \mu \mathrm{g} / \mathrm{mL} \mathrm{4}$ ', $6^{\prime}$-diamidino-2-phenylindole dihydrochloride (DAPI) at $37^{\circ} \mathrm{C}$ for $30 \mathrm{~min}$, changes in the nuclear morphology were observed under a fluorescence microscope (Olympus, Tokyo, Japan).

\section{Measurement of apoptotic cells by flow cytometry}

The quantitative analysis of apoptotic cell death caused by PAB or taxol treatment was analyzed using the Annexin V-FITC Apoptosis Detection Kit (KeyGEN BioTECH, Nanjing, China) following the manufacturer's protocol. The treated cells were harvested and rinsed with PBS twice, and then, they were stained with Annexin V-FITC and counterstained with PI in binding buffer at room temperature for $15 \mathrm{~min}$. The cells were analyzed with a FACScan flow cytometer.

\section{SA- $\beta$-Gal staining}

To detect senescent cells, a cellular senescence assay kit (Beyotime, Shanghai, China) was used according to the manufacturer's instructions. The cells were washed twice with PBS and incubated in $1 \mathrm{~mL}$ of fixing solution at room temperature for $15 \mathrm{~min}$. After removing the fixing solution and washing the fixed cells three times with PBS, the cells were stained with 1 $\mathrm{mL}$ of freshly prepared cell staining working solution at $37^{\circ} \mathrm{C}$ for at least $12 \mathrm{~h}$ under protection from light. After staining, the cells were washed, and the senescent cells were identified as the blue-stained cells using a light microscope (Olympus, Tokyo, Japan). At least 200 cells per field of vision were counted for each sample in three random fields to determine the percentage of SA- $\beta$-Gal-positive cells.

\section{Western blot analysis}

The cells were harvested, washed twice with PBS, and then lysed in whole cell RIPA lysis buffer (Beyotime, Haimen, Jiangsu, China) supplemented with PMSF (1 mmol/L). After a $15000 \times$ centrifugation at $4^{\circ} \mathrm{C}$ for $15 \mathrm{~min}$, the protein concentration was determined using the Bio-Rad protein assay reagent (Bio-Rad, Hercules, CA, USA). After denaturation with boiling water for $5 \mathrm{~min}$, the lysates, containing the same amount of protein, were separated by $12 \%$ SDS-PAGE and transferred 
onto a Millipore Immobilon ${ }^{\circledR}$-P Transfer Membrane (Millipore, Billerica, MA, USA). The membranes were soaked in 5\% skim milk and were then incubated with primary polyclonal antibodies overnight followed by incubation with the corresponding HRP-conjugated secondary antibodies. The blots were visualized using the SuperSignal ${ }^{\circledR}$ West Pico Chemiluminescent Substrate.

\section{Transfection of siRNA}

Human p53-targeted (p53-siRNA), p21-targeted (p21-siRNA) and negative control (control-siRNA) siRNAs were purchased from GenePharma (Suzhou, China). The cells were transfected with $5 \mathrm{nmol} / \mathrm{L}$ p53-, p21- or control-siRNA using siRNAMate $^{\mathrm{TM}}$ (GenePharma, Suzhou, China) according to the manufacturer's protocols. The transfected cells were used $24 \mathrm{~h}$ later for the subsequent experiments.

\section{Statistical analysis}

The data from at least three independent experiments are presented as the mean $\pm \mathrm{SD}$. The statistical comparisons were analyzed by a one-way ANOVA using the Statistics Package for Social Science soft-ware (version 13.0; SPSS, Chicago, IL, USA) and an LSD post hoc test was employed to assess the statistical significance of the differences between the controls and the treated groups. $P$ values $<0.05$ were considered statistically significant.

\section{Results}

\section{The effect of PAB on the growth of A549 cells}

The chemical structure of PAB is shown in Figure 1A. The results from the MTT assay indicated that $\mathrm{PAB}$ significantly inhibited the growth of A549 cells in a concentration-dependent manner (Figure 1B). The maximal growth inhibition reached at $20 \mu \mathrm{mol} / \mathrm{L}$; therefore, we used $20 \mu \mathrm{mol} / \mathrm{L}$ in the subsequent experiments.

\section{PAB-induced mitotic catastrophe in A549 cells}

A549 cells treated with $20 \mu \mathrm{mol} / \mathrm{L}$ PAB for the indicated time periods were subjected to a cell cycle distribution analysis on the basis of DNA content by FACScan flow cytometry. PAB caused $\mathrm{a} \mathrm{G}_{2} / \mathrm{M}$ phase arrest at day 1 , but the percentage of $\mathrm{G}_{2} / \mathrm{M}$-arrested cells decreased with prolonged $\mathrm{PAB}$ treatment (Figure 2A). Cyclin B1, an established marker of the $G_{2} / M$ phase, starts to appear in late $\mathrm{S}$ phase and accumulates in the cytoplasm during $\mathrm{M}$ phase ${ }^{[17]}$. Histone $\mathrm{H} 3$ plays a key role in mitotic chromosome condensation with phosphorylations at the residues Ser10 and Ser28 by Aurora-B kinase during mito$\operatorname{sis}^{[18]}$. PAB increased cyclin $\mathrm{B} 1$ and $\mathrm{p}$-Histone 3 expressions between 0 and $1 \mathrm{~d}$, but these markers sharply decreased from 2 to $4 \mathrm{~d}$ (Figure 2B). The results demonstrate that PAB disrupts the normal cell cycle progress, arresting the cells at the $\mathrm{G}_{2} / \mathrm{M}$ phase.

A prolonged mitotic arrest leads to mitotic catastrophe, which is characterized by the appearance of enlarged multinucleated cells with uncondensed chromatin ${ }^{[6]}$. As shown in Figure $2 \mathrm{~A}$, the proportion of polyploid cells ( $>4 \mathrm{~N}$ DNA) began to
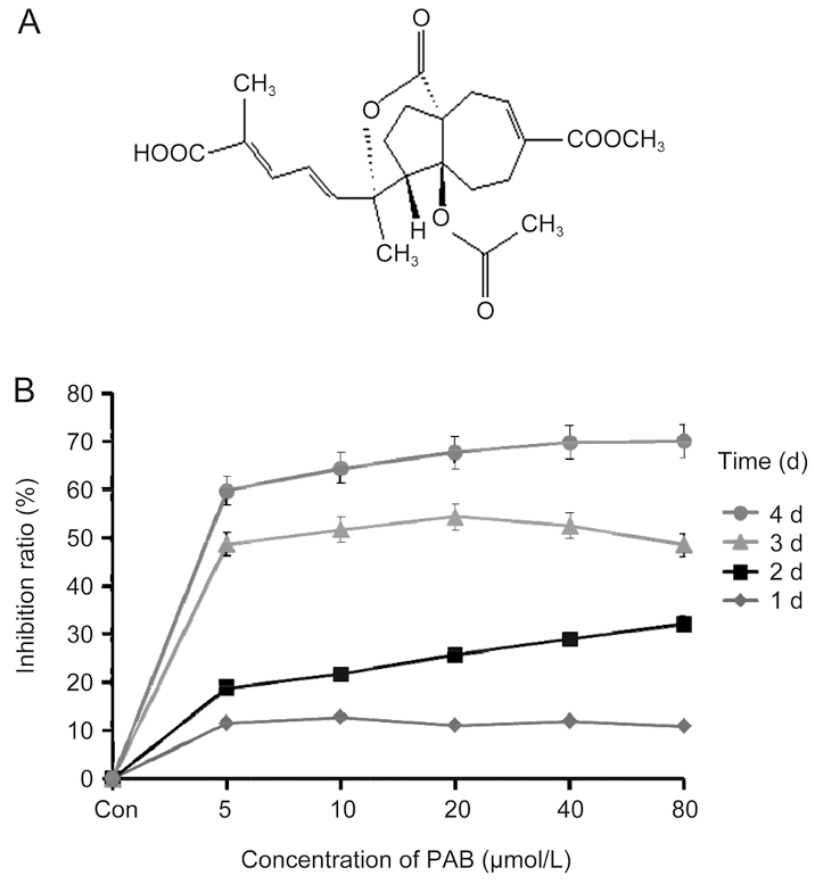

Figure 1. The effect of PAB on the growth of A549 cells. (A) The chemical structure of PAB. (B) The cells were cultured for $24 \mathrm{~h}$ and then incubated with different concentrations of PAB for 1, 2, 3 and $4 \mathrm{~d}$. Cell growth inhibition was determined by an MTT assay. Con: control. The data are presented as the mean $\pm \mathrm{SD}$ of three independent experiments.

increase at day 2. After PAB treatment, the cells exhibited the round morphology that is characteristic of mitotic cells at day 1 , but eventually became flat, enlarged and adherent at day 2 (Figure 2C, upper panels). To facilitate the visualization of the nuclear changes, the cells were stained with DAPI and examined with a fluorescence microscope after PAB treatment for the indicated periods. The multinucleated cells, which morphologically indicated mitotic catastrophe, increased from day 2 (Figure 2C, lower panels). These results suggest that $\mathrm{PAB}$ induces mitotic catastrophe in A549 cells after a prolonged $\mathrm{G}_{2} / \mathrm{M}$ arrest.

\section{Senescence is the fate of cells undergoing mitotic catastrophe in PAB-treated A549 cells}

The fate of cells undergoing mitotic catastrophe varies and can be apoptosis, necrosis or senescence ${ }^{[9]}$. Thus, we investigated whether the PAB-treated A549 cells were undergoing apoptosis. The number of subG ${ }_{1}$ cells, which is indicative of apoptotic or necrotic cells, did not significantly increase after treatment with PAB (Figure 2A). Furthermore, the combined use of Z-VAD-fmk (ZVAD), a known pan-caspase inhibitor, with $P A B$ did not ameliorate the inhibitory effect on cell proliferation in the PAB-treated A549 cells (Figure 3A). Annexin V-FITC and propidium iodide (PI) staining were used to confirm the induction of apoptosis or necrosis in A549 cells. The results showed that PAB treatment did not increase the apoptotic or necrotic ratio (Figure 3B). Moreover, $20 \mu \mathrm{mol} / \mathrm{L}$ 
A
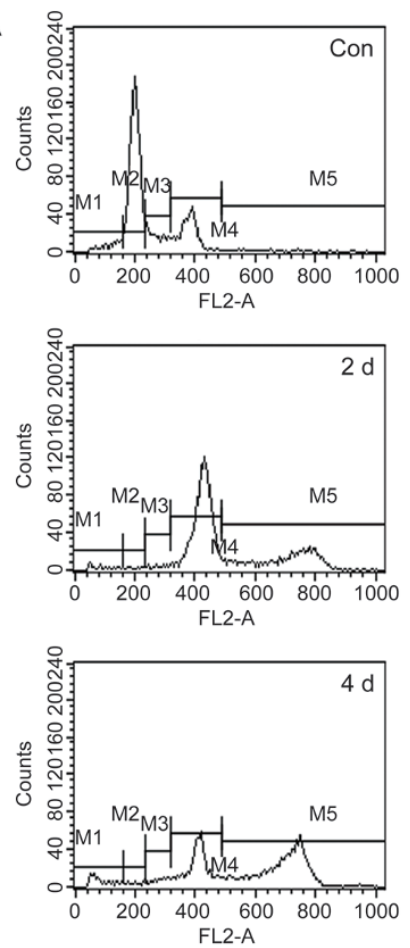

B

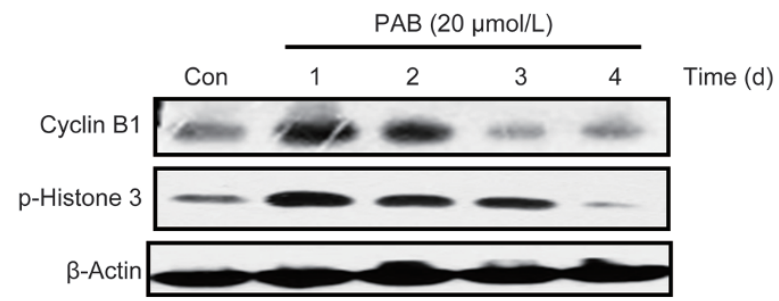

C

Con
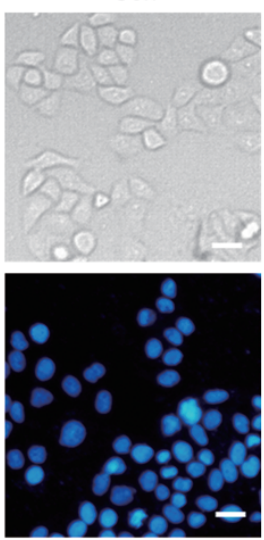
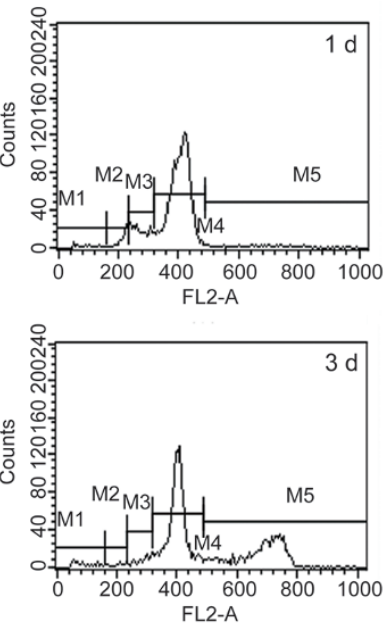

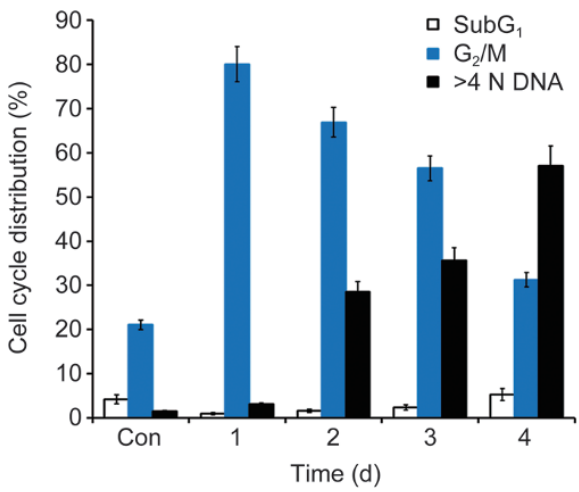

$2 d$
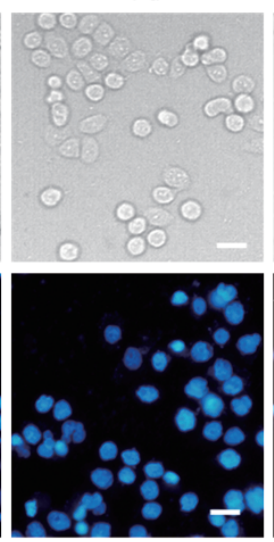
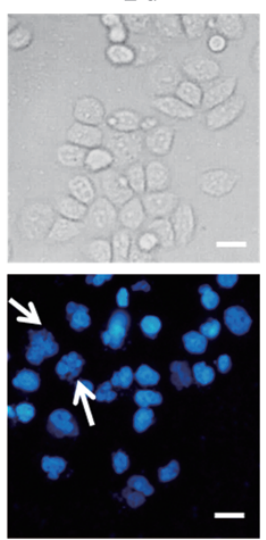

$3 d$
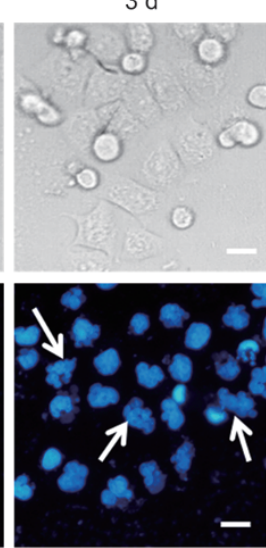
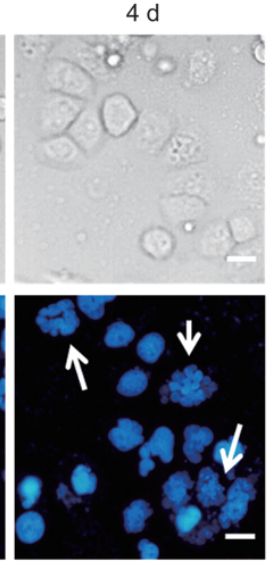

Figure 2. PAB-induced mitotic catastrophe in A549 cells. The cells were treated with $20 \mu \mathrm{mol} / \mathrm{L}$ PAB for $1,2,3$ and 4 d. (A) The DNA content was determined by flow cytometry after staining with PI, and the percentage of cells in specific cell cycle compartments was quantified. (B) Western blot analysis of cyclin B1 and p-Histone 3 (Ser 10) expression. (C) The cells were observed with a phase contrast microscope $(\times 200$ magnification, upper panels), and changes in the nuclear morphology were detected by DAPI staining ( $\times 200$ magnification, lower panels). The white arrows indicate multinucleated cells. The data are presented as the mean \pm SD of the results from three independent experiments. 
A

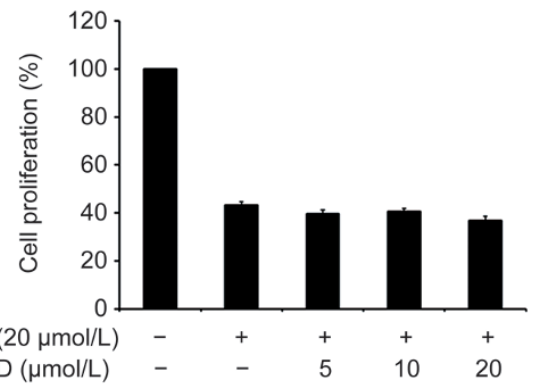

B

든
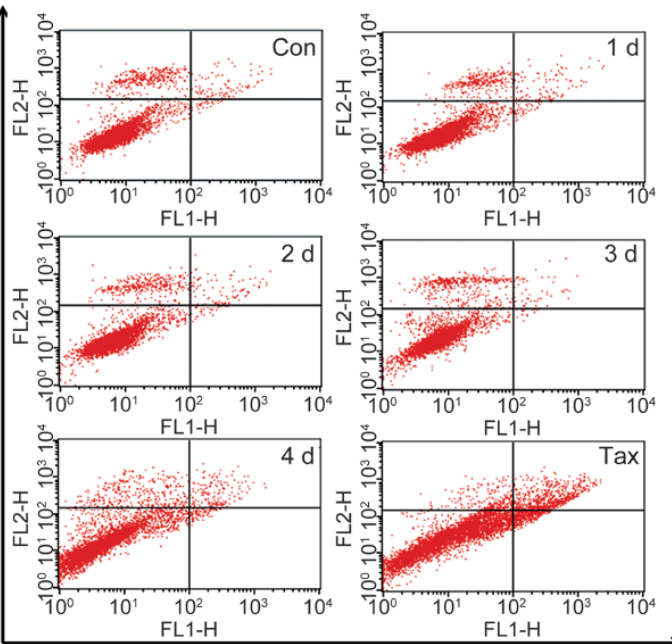

Annexin V-FITC

D
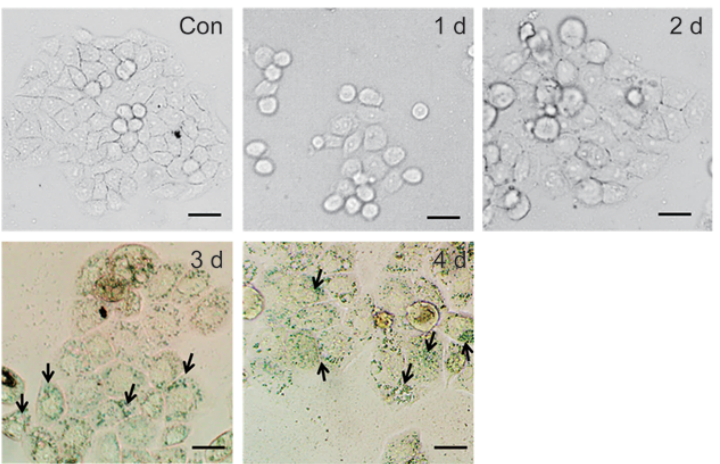

E

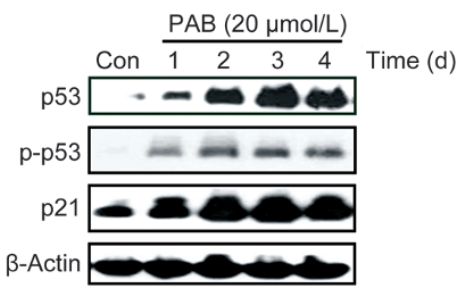

C
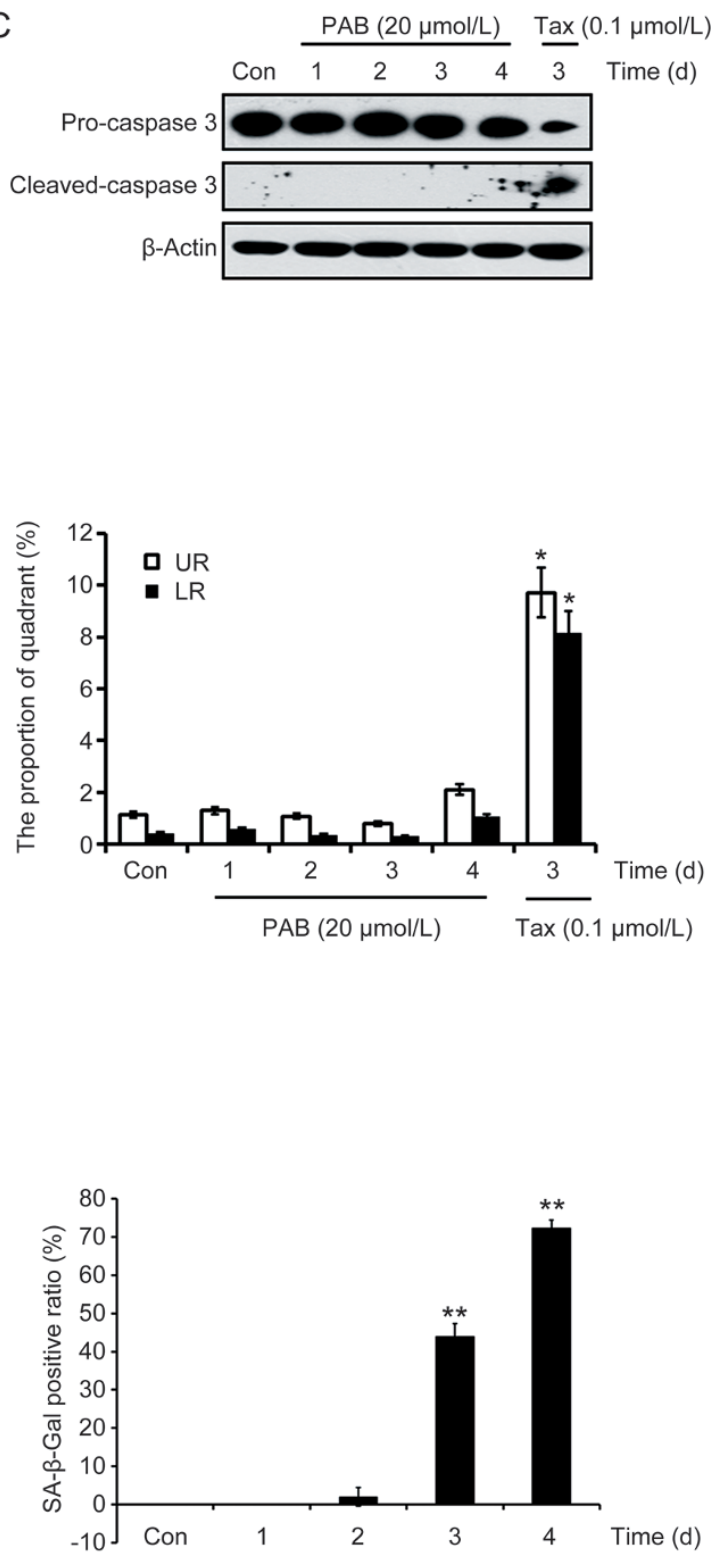

Figure 3. Senescence is the fate of cells undergoing mitotic catastrophe in PAB-treated A549 cells. (A) The cells were incubated with $20 \mu$ mol/L PAB or combined with different concentrations of Z-VAD for $3 \mathrm{~d}$. Cell proliferation was measured by an MTT assay. (B, C) The cells treated with $20 \mu$ mol/L PAB or $0.1 \mu \mathrm{mol} / \mathrm{L}$ taxol at the indicated time points. Taxol (Tax) was used as a positive control. (B) The induction of apoptosis was determined by a flow cytometric analysis with Annexin V-FITC and PI-staining. The cells in the lower right (LR) quadrant indicate Annexin-positive/PI negative, early apoptotic cells. The cells in the upper right (UR) quadrant indicate Annexin-positive/PI-positive, late apoptotic or necrotic cells. The LR or UR ratio is indicated in the right panel. (C) The protein expression of caspase-3 was determined by a Western blot analysis after PAB or Tax treatment. (D, E) The cells were treated with $20 \mu \mathrm{mol} / \mathrm{L} \mathrm{PAB}$ for 1, 2, 3 and $4 \mathrm{~d}$. (D) The senescent cells were examined by SA- $\beta$-Gal staining $(\times 200$ magnification). The ratio of the SA$\beta$-Gal positive cells is shown in the right panel. Black arrows: typical SA- $\beta$-Gal positive cells. (E) The protein levels of p53, p-p53 (Ser 15), and p21 were examined by Western blot analysis. The data are presented as the mean \pm SD of three independent experiments. ${ }^{*} P<0.05$, ${ }^{* *} P<0.01$ vs control group. 
PAB failed to induce caspase 3 activation between day 0 and day 4 by Western blot. In contrast, taxol treatment caused an increase in cleaved-caspase 3 (activated form) (Figure 3C). Together, these data demonstrate that PAB-treated cells undergoing mitotic catastrophe are not going through apoptosis or necrosis.

In Figure 2C, the appearance of flat, enlarged, multinucleated and adherent cells is indicative of senescence. Therefore, we speculated that senescence might be the fate of cells undergoing mitotic catastrophe. Senescent cells display several characteristics, such as an increased activity of senescenceassociated $\beta$-galactosidase (SA- $\beta$-Gal) and an increased expression of $\mathrm{p}^{[19]}$. P16 is involved in Rb-associated cell cycle regulations and thus, the induction of senescence. However, the p16 gene is homozygously deleted in A549 cells ${ }^{[20]}$. SA- $\beta$ Gal staining was used to detect the senescent cells. The results show that SA- $\beta$-Gal positive cells appeared at days 3 and 4 (Figure 3D). Concomitantly, multinucleated cells appeared in the PAB-treated A549 cells at days 3 and 4 (Figure 2A, 2C). A Western blot analysis showed that the protein levels of p53, p-p53 and p21 increased in a time-dependent manner (Figure $3 \mathrm{E})$. Taken together, the fate of cells undergoing mitotic catastrophe is senescence in the PAB-treated A549 cells.

\section{p53 plays an important role in PAB-induced senescence in A549 cells}

Previous studies show that p53 is a key regulator of senescence induction $^{[14]}$. To determine whether $\mathrm{p} 53$ is required for PAB-induced senescence, p53 was knocked down by siRNA in A549 cells. The siRNA transfection efficiency was detected by a Western blot (Figure 4A). As shown in Figure 4B, the knockdown of p53 expression decreased the ratio of polyploid cells but raised the number of subG $\mathrm{G}_{1}$ cells between days 2 and 3 (Figure 4B). Interestingly, p53 inhibition had little effect on PAB-induced $\mathrm{G}_{2} / \mathrm{M}$ arrest at day 1 (Figure 4B, 4D). Moreover, the SA- $\beta$-Gal staining showed that the suppression of p53 was associated with decreased senescence induction in the PAB-treated A549 cells (Figure 4C). In addition, a Western blot assay also revealed that p53 downregulation reduced the protein levels of p53, p-p53 and p21 at day 3. In contrast, caspase 3 expression was elevated (Figure 4D). Thereafter, p21 was knocked down by siRNA, and the transfection efficiency is shown in Figure 4A. Consistently, the knockdown of p21 attenuated PAB-induced senescence (Figure 4E, 4F). These results suggest that $\mathrm{p} 53$ plays an important role in regulating PAB-induced senescence in A549 cells.

To investigate whether the observation of mitotic catastrophe and the subsequent senescence is specific for the A549 cells, we examined the effect of PAB on H460 cells, which is another p53 wild type cell line. Our data suggested that similar observations were induced in the PAB-treated H460 cells. Namely, PAB-arrested the $\mathrm{H} 460$ cells at the $\mathrm{G}_{2} / \mathrm{M}$ phase at day 1 , caused mitotic catastrophe at day 2 and senescence was observed between days 3 and 4 (Figure 5A-5D). Meanwhile, p53 and p21 inhibition also decreased PAB-induced senescence in the H460 cells (Figure 5E-5G). These results suggest that PAB-induced senescence might require functional p53. To further examine the role of p53 in PAB-induced senescence in the A549 cells, we investigated whether H1299 cells (p53 null) were affected by PAB because the H460 and H1299 cells are p16-deficient ${ }^{[21]}$. After treatment with PAB, the H1299 cells initially exhibited the round morphology that is characteristic of mitotic cells but eventually died via apoptosis (Figure $6 \mathrm{~A}$, upper panels). PAB treatment produced multinucleated and apoptotic cells during the same time period (days 2 to 4) in the H1299 cells (Figure 6A, lower panels). A cell cycle analysis demonstrated that PAB arrested the H1299 cells at the $G_{2} / M$ phase at day 1 , and the percentage of polyploid cells increased slightly between days 2 and 4 . Meanwhile, the ratio of subG ${ }_{1}$ cells, which is indicative of apoptosis, is gradually elevated from day 2 to 4 (Figure 6B). However, senescent cells with positive SA- $\beta$-Gal staining were not observed (Figure 6C). Furthermore, a Western blot analysis of the protein levels related to the cell cycle, apoptosis and senescence (Figure 6D) showed that the PAB-treated H1299 cells suffered mitotic catastrophe and died via apoptosis. These results suggest that the inhibition of p53 activity diminished PAB-induced senescence. Taken together, p53 is indispensable for PAB-induced senescence in A549 cells.

\section{Discussion}

PAB, a microtubule-binding drug, inhibits microtubule polymerization as colchicine does ${ }^{[6]}$. Microtubule-targeted drugs cause the mitotic arrest of tumor cells. These arrested cells might exit mitosis and slip into the next cell cycle without undergoing complete chromosomal segregation and cell division $^{[22]}$. Mitotic slippage is correlated with cyclin B1 degradation $^{[23]}$, leading to an increase in the number of polyploid cells. The increased number of multinucleated A549 cells after PAB treatment in this study (Figure 2) is consistent with the effects of microtubule-targeted drugs in general.

Cells arrested in mitosis upon the activation of mitotic catastrophe have different fates, including death during mitosis, the entrance into the subsequent cell cycle followed by cell death, or an exit from mitosis followed by senescence ${ }^{[24]}$. A prolonged mitotic arrest or mitotic slippage usually leads to cell death. Several studies reported that PAB induced apoptosis in many cancer cell lines, including MCF7, A375 and L929 cells $^{[2,5,6]}$. However, PAB-induced mitotic catastrophe following a $\mathrm{G}_{2} / \mathrm{M}$ arrest in A549 cells leads to senescence but not cell death (apoptosis or necrosis). Once the cells become senescent, they become resistant to cell-death signals (apoptosis resistance).

Our previous study indicated that the ATM-p53 pathway caused $\mathrm{a} \mathrm{G}_{2} / \mathrm{M}$ arrest in PAB-treated HeLa cells ${ }^{[4]}$. Meanwhile, there are two main pathways for mitotic arrest, the ATMp53-p21 and the ATM-Chk2-cdc25 pathways. However, in response to camptothecin, the $\mathrm{H} 1299$ cells (p53-null) arrested in the $G_{2} / M$ phase through the ATM pathway ${ }^{[25]}$. Therefore, we speculated that $P A B$ induced the $G_{2} / M$ arrest via the ATM-Chk2-cdc25 pathway in A549 cells. Although the PAB arrested the cells at the $\mathrm{G}_{2} / \mathrm{M}$ phase, there was little correla- 
A

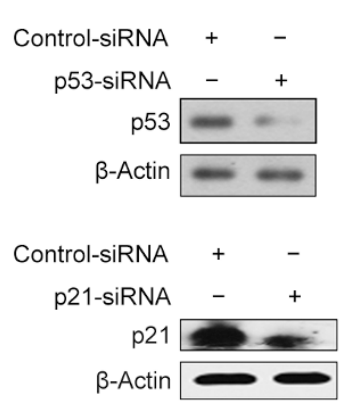

C

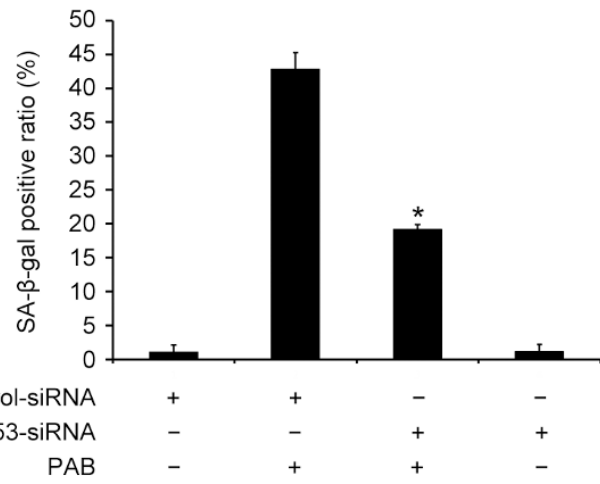

$E$

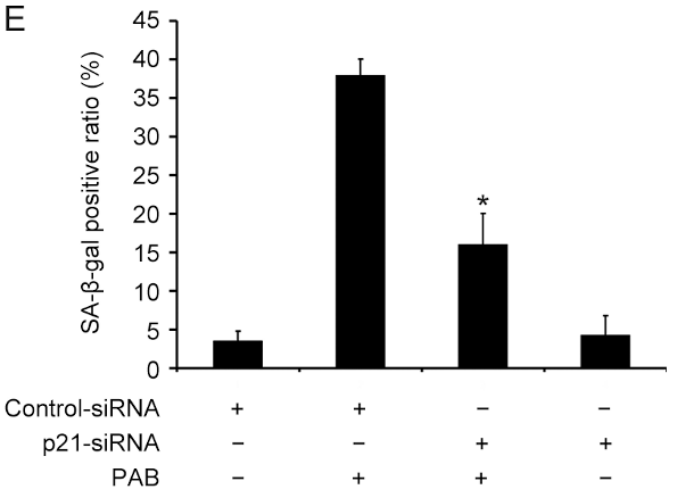

B

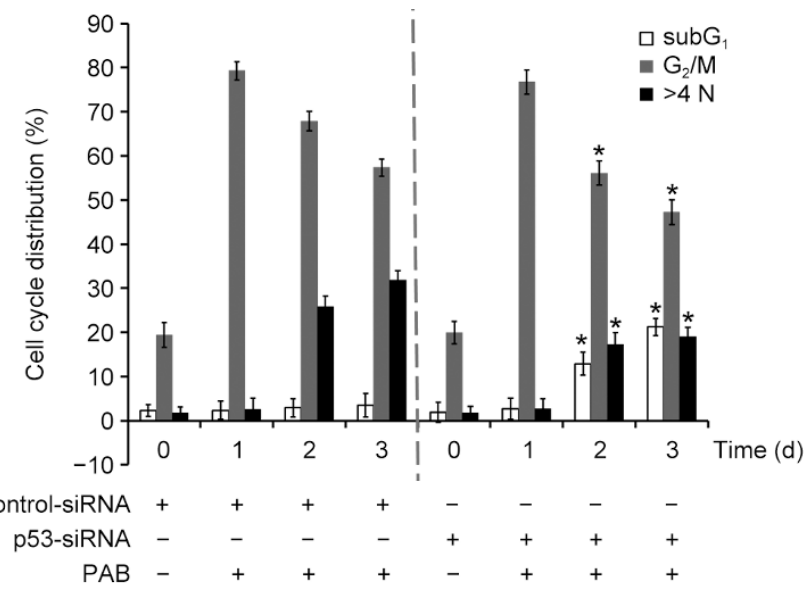

$\mathrm{D}$

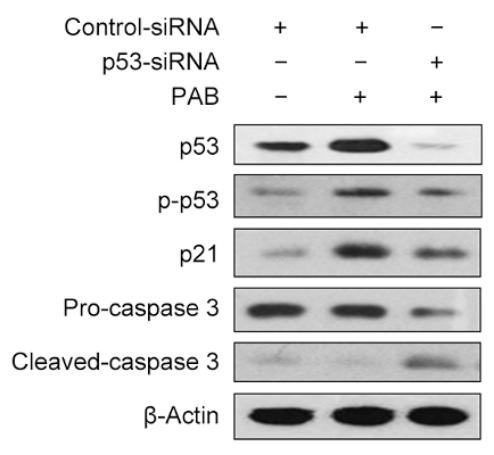

$\mathrm{F}$

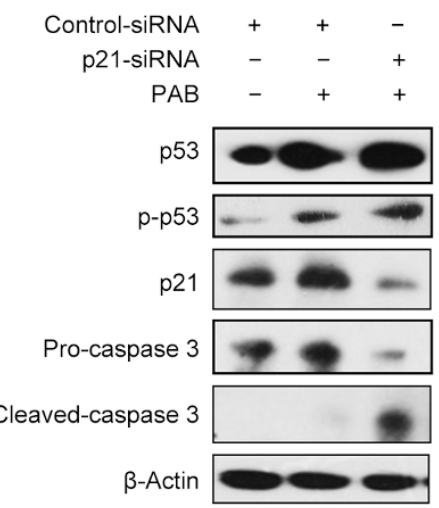

Figure 4. p53 inhibition attenuated PAB-induced senescence in A549 cells. (A-D) A549 cells were transfected with control or p53 siRNA for 24 h. (A) Western blot analysis was utilized to detect the transfection efficiency. (B) The cells were stained with PI and measured by flow cytometry. The ratios of the M1, M4 and M5 gated cells were calculated as the subG $G_{1}, G_{2} / M$ and multinucleation ratio, respectively. (C) The SA- $\beta$-Gal staining was used to examine the percentage of senescent cells. The ratio of the SA- $\beta$-Gal positive cells is shown. (D) The protein levels of p53, p-p53 (Ser 15), p21 and caspase-3 were evaluated by Western blot. (E, F) A549 cells were transfected with control or p21 siRNA for 24 h. (E) The senescent cells were determined using SA- $\beta$-Gal staining. The ratio of the SA- $\beta$-Gal positive cells is exhibited. (F) Western blot was utilized to examine the expression of p53, p-p53 (Ser 15), p21 and caspase-3. The data are presented as the mean \pm SD of three independent experiments. ${ }^{*} P<0.05$ vs PAB-treated group.

tion with p53 or p21. In this study, the increased p53 and p21 did not induce $\mathrm{G}_{1} / \mathrm{S}$ arrest. Therefore, we thought that the expressions of p53 and p21 might contribute to other types of programmed cell death, and the detailed mechanism should be further studied.
As an anti-microtubule drug, PAB arrests many cancer cell lines in the $\mathrm{G}_{2} / \mathrm{M}$ phase. The arrested cells undergo apoptotic cell death; however, a fraction of them survive and resume the cell-cycle progression ${ }^{[26]}$. Thus, PAB might indirectly induce DNA damage. 
A

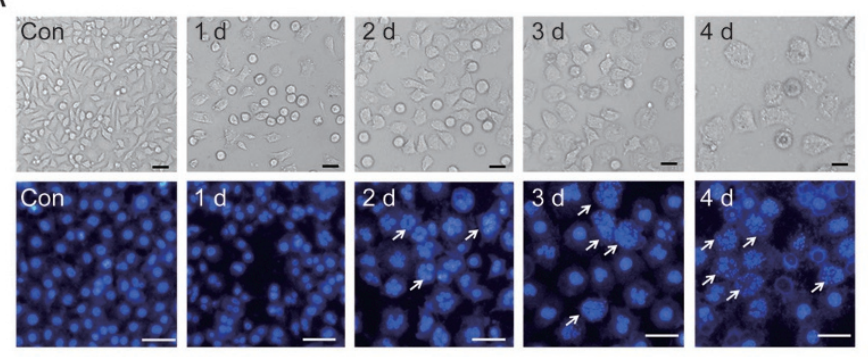

C

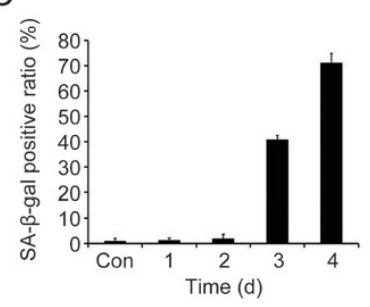

E

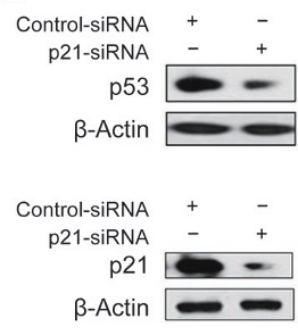

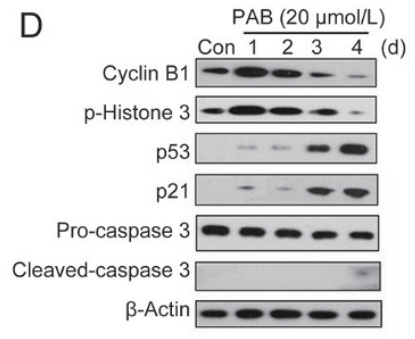

$\mathrm{F}$

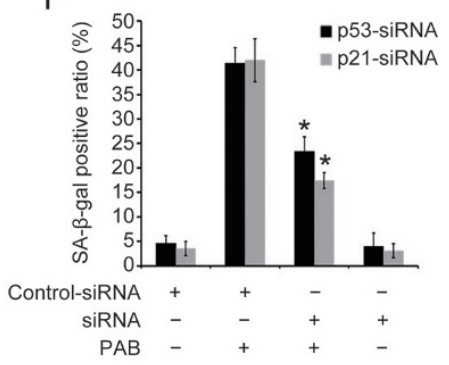

B
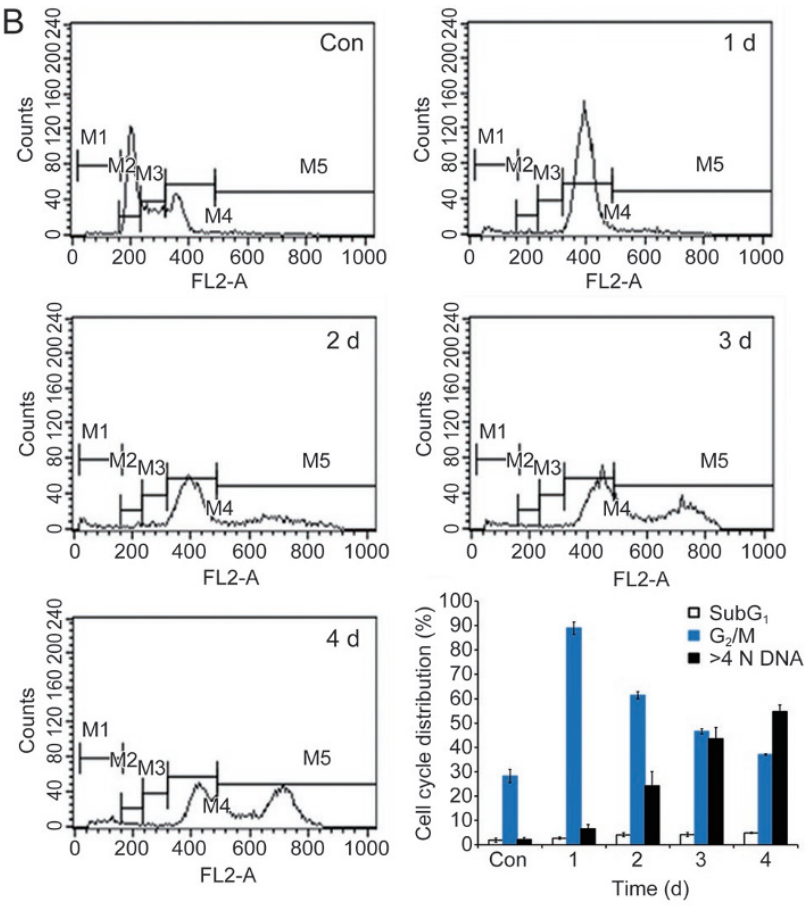

G

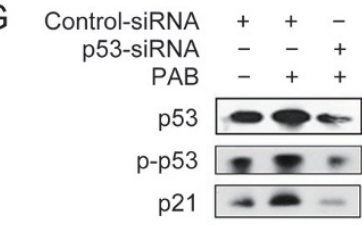

Pro-caspase 3

Cleaved-caspase 3

$\beta$-Actin

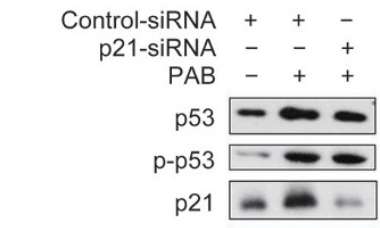

Pro-caspase 3

Cleaved-caspase 3

$\beta$-Actin

Figure 5. PAB-induced mitotic catastrophe is followed by senescence in $\mathrm{H} 460$ cells. (A-D) The cells were incubated with $20 \mu \mathrm{mol} / \mathrm{L}$ PAB for the indicated time periods between $\mathrm{d} 0$ and $\mathrm{d} 4$. (A) The cells were observed with a phase contrast microscope $(\times 100$ magnification, upper panels), and changes in the nuclear morphology were detected by DAPI staining ( $\times 200$ magnification, lower panels). The white arrows indicate multinucleated cells. (B) The percent of cells in various phases of the cell cycle was calculated by flow cytometry. $(\mathrm{C})$ The senescent cells were examined by SA- $\beta$ Gal staining. The ratio of the SA-B-Gal positive cells is shown. (D) The protein levels of cyclin B1, p-Histone 3 (Ser10), p53, p21 and caspase-3 were evaluated by a Western blot. (E-G) H460 cells were transfected with control, p53 or p21 siRNA for 24 h. (E) A Western blot analysis was utilized to detect the transfection efficiency. (F) The senescent cells were determined by using SA- $\beta$-Gal staining. The ratio of the SA- $\beta$-Gal positive cells is shown. (G) Western blot was applied to examine the expression of p53, p-p53 (Ser 15), p21 and caspase-3. The data are presented as the mean \pm SD of three independent experiments. ${ }^{*} P<0.05$ vs PAB-treated group.

The relation between mitotic catastrophe and senescence is still unclear. Mitotic catastrophe, resulting from abnormal mitosis, usually ends in the formation of large cells accompanied by multinucleation and chromatin decondensation ${ }^{[27]}$. Senescent cells develop distinctly and have a recognizably flattened and enlarged morphology with an increased cytoplasmic granularity, the presence of polyploidy and the expression of senescence-associated $\beta$-galactosidase ${ }^{[28]}$. Mitotic catastrophe and senescence share the same characteristics, including the enlargement and multinucleation of the cells. In a limited number of cases, mitotic catastrophe results in senescence ${ }^{[29,30]}$. P31 ${ }^{\text {comet }[30]}$ and PAB affect A549 cells in the same way in that both induce cellular senescence through mitotic catastrophe.
A number of the SA- $\beta$-gal positive cells contain multiple nuclei. However, senescence induction is not found in the other tumor cell lines ${ }^{[30]}$.

Our previous studies demonstrated that the same concentration of PAB induced senescence in L929 cells following mitotic catastrophe but was accompanied by apoptosis ${ }^{[31]}$. In other tumor cell lines, such as HeLa, A375 and human colorectal carcinoma HCT116 cells, PAB did not induce senescence ${ }^{[2,3,6]}$. These cells exhibited apoptosis after PAB treatment. The observation in A549 cells that senescence is the only fate following mitotic catastrophe by treatment with $\mathrm{PAB}$ is shared with H460 cells (p53 positive), but not with H1299 cells (p53 null), implying that p53 is indispensable for senescence induc- 

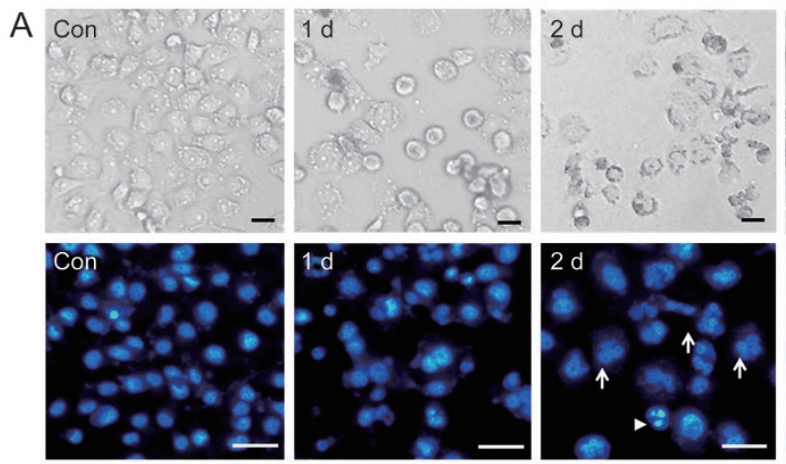
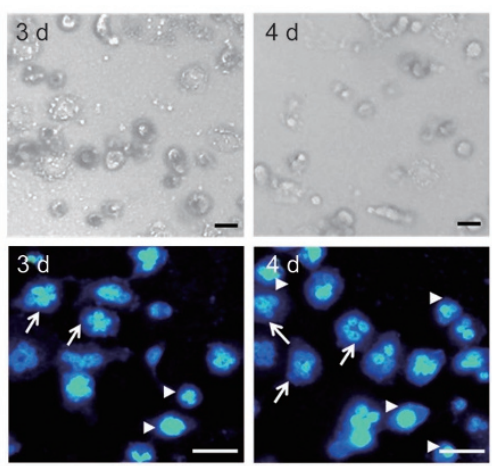

B
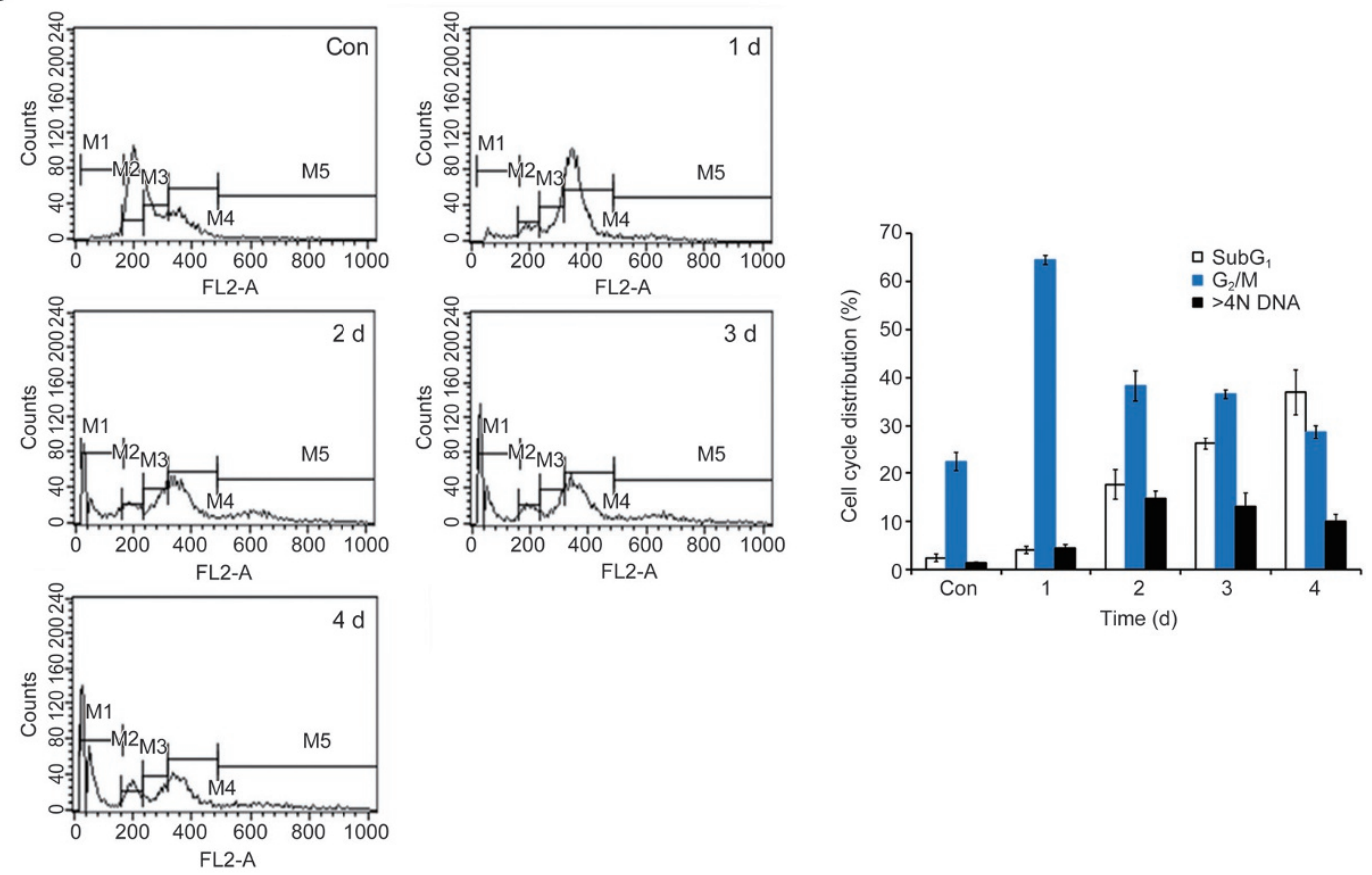

C

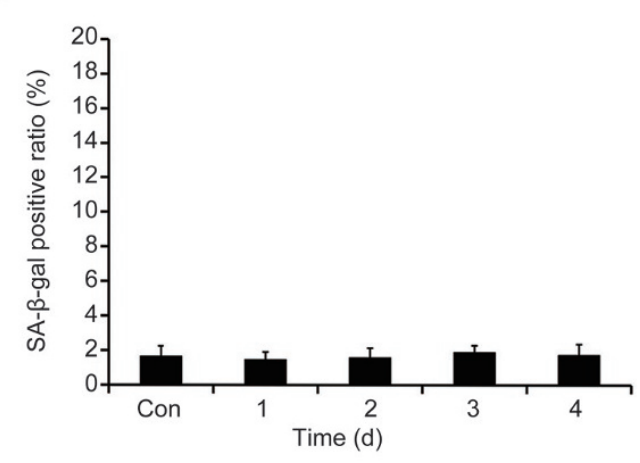

D

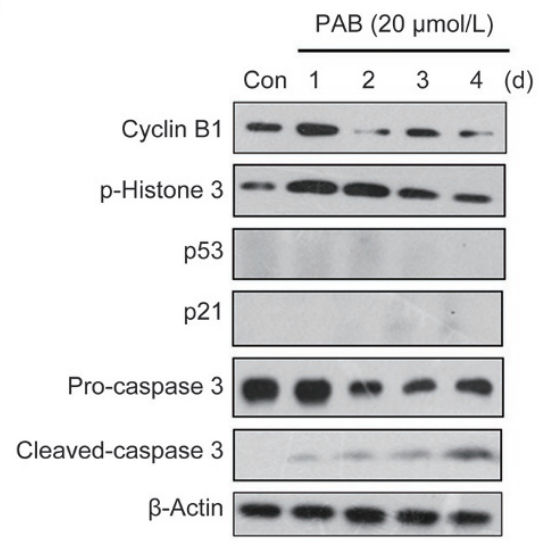

Figure 6. The PAB-treated $\mathrm{H} 1299$ cells undergoing mitotic catastrophe die via apoptosis. The cells were incubated with PAB for 0-4 d. (A) The cells were observed with a phase contrast microscope ( $\times 100$ magnification, upper panels), and changes in the nuclear morphology were detected by DAPI staining ( $\times 200$ magnification, lower panels). The white arrows indicate multinucleated cells, and the arrowheads denote apoptotic cells. (B) The cell cycle distribution, based on a flow cytometry analysis, was quantitated. (C) The senescent cells were examined by SA- $\beta$-Gal staining. The ratio of the SA- $\beta$-Gal positive cells is shown. (D) The protein levels of cyclin B1, p-Histone 3 (Ser 10), p53, p21 and caspase-3 were examined by Western blot. The data are presented as the mean $\pm \mathrm{SD}$ of three independent experiments. 
tion by PAB. It is yet unclear what determines whether cells undergo senescence or apoptosis. Most cells respond in the both ways, senescence and apoptosis, where p53 is probably their common regulator ${ }^{[32]}$. In some cases, p53 might preferentially activate genes that arrest proliferation rather than those that facilitate apoptosis ${ }^{[33]}$. However, Guan et al reported that PAB induced apoptosis in A549 cells at a high cell density ${ }^{[34]}$, suggesting that the cellular environment is also a major factor of cell fate. From a different point of view, it will be intriguing to know whether the levels of p53 or/and p-p53 are required for the induction of cell senescence.

In L929 cells, a fraction of the PAB cells arrested in mitosis eventually died via apoptosis ${ }^{[6]}$. Moreover, similar results were shown in the PAB-treated H1299 cells, and the induction of apoptosis was in a p53-independent manner.

Apoptosis induction in cancer cells is one of the most promising anti-cancer strategies, which aims to kill the tumor cells with no or minimal damage to the normal cells ${ }^{[35]}$. Higher levels of damage may trigger apoptosis and adverse effects on other normal tissues, which remains an important issue. Chronic administration of low doses of drugs could induce senescence with low toxicity-related side effects and immune stimulation. Cellular senescence in cancer therapy has been reported in several studies ${ }^{[14,36]}$. In contrast to apoptosis, cells undergoing senescence have less side effects ${ }^{[16]}$. Moreover, therapy-induced senescent cells are eventually cleared by the immune cells, resulting in efficient tumor suppression ${ }^{[15]}$. Therefore, senescence might provide a better approach for the management of some cancers. However, cellular senescence in cancer therapy has some drawbacks because senescent cells, as living cells, produce tumor cell growth promoting factors $^{[37]}$. Moreover, senescent cells secret cytokines (such as IL-6 and IL-8), which impact the surrounding cancer cells and the tumor microenvironment to cause chemoresistance ${ }^{[38]}$. Understanding the behavior of senescent cells will give us a better cancer therapy in the future.

\section{Author contribution}

Guo-dong YAO, Min QI, Si-miao FAN and Takashi IKEJIMA designed the research; Guo-dong YAO, Jing YANG, Qiang LI and Ye ZHANG performed the research; Shin-Ichi TASHIRO and Satoshi ONODERA contributed some reagents; Guodong YAO analyzed the data and wrote the paper; Toshihiko HAYASHI and Takashi IKEJIMA revised the paper.

\section{References}

1 Yan Z, Hua H, Xu Y, Samaranayake LP. Potent antifungal activity of pure compounds from traditional chinese medicine extracts against six oral candida species and the synergy with fluconazole against azole-resistant candida albicans. Evid Based Compl Alt Med 2012; 2012: 106583.

2 Gong XF, Wang MW, Tashiro S, Onodera S, Ikejima T. Pseudolaric acid $\mathrm{B}$ induces apoptosis through p53 and $\mathrm{Bax} / \mathrm{Bcl}-2$ pathways in human melanoma A375-S2 cells. Arch Pharm Res 2005; 28: 68-72.

3 Gong X, Wang M, Tashiro S, Onodera S, Ikejima T. Involvement of JNKinitiated p53 accumulation and phosphorylation of p53 in pseudolaric acid B induced cell death. Exp Mol Med 2006; 38: 428-34.
4 Yao G, Qi M, Ji X, Fan S, Xu L, Hayashi T, et al. ATM-p53 pathway causes $\mathrm{G}_{2} / \mathrm{M}$ arrest, but represses apoptosis in pseudolaric acid B-treated HeLa cells. Arch Biochem Biophys 2014; 558: 51-60.

5 Yu JH, Cui Q, Jiang YY, Yang W, Tashiro S, Onodera S, et al. Pseudolaric acid $B$ induces apoptosis, senescence, and mitotic arrest in human breast cancer MCF-7. Acta Pharmacol Sin 2007; 28: 1975-83.

6 Qi M, Yao G, Fan S, Cheng W, Tashiro S, Onodera S, et al. Pseudolaric acid $B$ induces mitotic catastrophe followed by apoptotic cell death in murine fibrosarcoma L929 cells. Eur J Pharmacol 2012; 683: 16-26.

7 Ma G, Chong L, Li XC, Khan IA, Walker LA, Khan SI. Selective inhibition of human leukemia cell growth and induction of cell cycle arrest and apoptosis by pseudolaric acid B. J Cancer Res Clin Oncol 2010; 136: 1333-40.

8 Portugal J, Mansilla S, Bataller M. Mechanisms of drug-induced mitotic catastrophe in cancer cells. Curr Pharm Des 2010; 16: 6978.

9 Blagosklonny MV. Mitotic arrest and cell fate: why and how mitotic inhibition of transcription drives mutually exclusive events. Cell Cycle 2007; 6: 70-4.

10 Vakifahmetoglu $\mathrm{H}$, Olsson $\mathrm{M}$, Zhivotovsky B. Death through a tragedy: mitotic catastrophe. Cell Death Differ 2008; 15: 1153-62.

11 Baker DJ, Wijshake T, Tchkonia T, LeBrasseur NK, Childs BG, van de Sluis $B$, et al. Clearance of $\mathrm{p} 16$ Ink4a-positive senescent cells delays ageing-associated disorders. Nature 2011; 479: 232-6.

12 van Deursen JM. The role of senescent cells in ageing. Nature 2014; 509: 439-46.

13 Campisi J. Cellular senescence: putting the paradoxes in perspective. Curr Opin Genet Dev 2011; 21: 107-12.

14 Schmitt CA, Fridman JS, Yang M, Lee S, Baranov E, Hoffman RM, et al. A senescence program controlled by $\mathrm{p} 53$ and p16INK4a contributes to the outcome of cancer therapy. Cell 2002; 109: 335-46.

15 Xue W, Zender L, Miething C, Dickins RA, Hernando E, Krizhanovsky $\mathrm{V}$, et al. Senescence and tumour clearance is triggered by $\mathrm{p} 53$ restoration in murine liver carcinomas. Nature 2007; 445: 656-60.

16 Ewald JA, Desotelle JA, Wilding G, Jarrard DF. Therapy-induced senescence in cancer. J Natl Cancer Inst 2010; 102: 1536-46.

17 Sherr CJ. Cancer cell cycles. Science 1996; 274: 1672-7.

18 Hendzel MJ, Wei Y, Mancini MA, Van Hooser A, Ranalli T, Brinkley BR, et al. Mitosis-specific phosphorylation of histone $\mathrm{H} 3$ initiates primarily within pericentromeric heterochromatin during $G_{2}$ and spreads in an ordered fashion coincident with mitotic chromosome condensation. Chromosoma 1997; 106: 348-60.

19 Kuilman T, Michaloglou C, Mooi WJ, Peeper DS. The essence of senescence. Genes Dev 2010; 24: 2463-79.

20 Iwakawa R, Kohno T, Anami Y, Noguchi M, Suzuki K, Matsuno Y, et al. Association of $\mathrm{p} 16$ homozygous deletions with clinicopathologic characteristics and EGFR/KRAS/p53 mutations in lung adenocarcinoma. Clin Cancer Res 2008; 14: 3746-53.

21 Kataoka M, Wiehle S, Spitz F, Schumacher G, Roth JA, Cristiano RJ. Down-regulation of bcl-2 is associated with p16INK4-mediated apoptosis in non-small cell lung cancer cells. Oncogene 2000; 19: 1589-95.

22 Di Leonardo A, Khan SH, Linke SP, Greco V, Seidita G, Wahl GM. DNA rereplication in the presence of mitotic spindle inhibitors in human and mouse fibroblasts lacking either p53 or pRb function. Cancer Res 1997; 57: 1013-9.

23 Brito DA, Rieder CL. Mitotic checkpoint slippage in humans occurs via cyclin B destruction in the presence of an active checkpoint. Curr Biol 2006; 16: 1194-200.

24 Vitale I, Galluzzi L, Castedo M, Kroemer G. Mitotic catastrophe: a mechanism for avoiding genomic instability. Nat Rev Mol Cell Biol 
2011; 12: 385-92.

25 Roberson RS, Kussick SJ, Vallieres E, Chen SY, Wu DY. Escape from therapy-induced accelerated cellular senescence in p53-null lung cancer cells and in human lung cancers. Cancer Res 2005; 65: 2795-803.

26 Nitta M, Tsuiki H, Arima Y, Harada K, Nishizaki T, Sasaki K, et al. Hyperploidy induced by drugs that inhibit formation of microtubule promotes chromosome instability. Genes Cells 2002; 7: 151-62.

27 Roninson IB, Broude EV, Chang BD. If not apoptosis, then what? Treatment-induced senescence and mitotic catastrophe in tumor cells. Drug Resist Updat 2001; 4: 303-13.

28 Dimri GP, Lee X, Basile G, Acosta M, Scott G, Roskelley C, et al. A biomarker that identifies senescent human cells in culture and in aging skin in vivo. Proc Natl Acad Sci U S A 1995; 92: 9363-7.

29 Eom YW, Kim MA, Park SS, Goo MJ, Kwon HJ, Sohn S, et al. Two distinct modes of cell death induced by doxorubicin: apoptosis and cell death through mitotic catastrophe accompanied by senescencelike phenotype. Oncogene 2005; 24: 4765-77.

30 Yun M, Han YH, Yoon SH, Kim HY, Kim BY, Ju YJ, et al. p31comet Induces cellular senescence through p21 accumulation and Mad2 disruption. Mol Cancer Res 2009; 7: 371-82.

31 Qi M, Fan S, Yao G, Li Z, Zhou H, Tashiro S, et al. Pseudolaric acid B-induced autophagy contributes to senescence via enhancement of
ROS generation and mitochondrial dysfunction in murine fibrosarcoma L929 cells. J Pharmacol Sci 2013; 121: 200-11.

32 Seluanov A, Gorbunova V, Falcovitz A, Sigal A, Milyavsky M, Zurer I, et al. Change of the death pathway in senescent human fibroblasts in response to DNA damage is caused by an inability to stabilize p53. Mol Cell Biol 2001; 21: 1552-64.

33 Chang BD, Swift ME, Shen M, Fang J, Broude EV, Roninson IB. Molecular determinants of terminal growth arrest induced in tumor cells by a chemotherapeutic agent. Proc Natl Acad Sci U S A 2002; 99: 389-94.

34 Guan T, Yang Y. Role of pseudolaric acid B in A549 lung cancer cell proliferation and apoptosis. Mol Med Rep 2014; 9: 144-8.

35 Ghobrial IM, Witzig TE, Adjei AA. CA Cancer J Clin 2005; 55: 178-94.

36 Dorr JR, Yu Y, Milanovic M, Beuster G, Zasada C, Dabritz JH, et al. Synthetic lethal metabolic targeting of cellular senescence in cancer therapy. Nature 2013; 501: 421-5.

37 Cahu J, Bustany S, Sola B. Senescence-associated secretory phenotype favors the emergence of cancer stem-like cells. Cell Death Dis 2012; 3: e446.

38 Coppe JP, Desprez PY, Krtolica A, Campisi J. The senescenceassociated secretory phenotype: the dark side of tumor suppression. Annu Rev Pathol 2010; 5: 99-118. 